\title{
Alkaline phosphatase and peroxidase for double immunoenzymatic labelling of cellular constituents
}

\author{
D. Y. MASON AND RITA SAMMONS \\ From the University of Oxford, Department of Pathology, Radcliffe Infirmary, Oxford, UK
}

SUMMARY The use of alkaline phosphatase in an immunoenzymatic procedure for the localisatio of antigens in paraffin sections or cell smears is described. The results of this method, when applied to the detection of immunoglobulins, lysozyme, or lactoferrin, were comparable in intensity and clarity to those obtained with the PAP immunoperoxidase procedure. Furthermore, double imb munoenzymatic labelling (with alkaline phosphatase and peroxidase) of two cellular constituent in a tissue section is possible, the brown peroxidase reaction product contrasting well with the blue alkaline phosphatase product. Since the two antibody 'sandwiches' are applied simultaneousl rather than sequentially the total duration of this double immunostaining procedure is only a few minutes longer than that required for detection of a single antigen.

It was also found that the unlabelled antibody immunohistological procedure (whether used ino conjunction with alkaline phosphatase or peroxidase) can be shortened without loss of sensitiviti by carrying out two of the incubation steps simultaneously.

Immunoperoxidase techniques for the detection of antigens in human tissues have gained wide acceptance in recent years because of their superiority, in terms of histological detail, over immunofluorescent methods. Furthermore, it has become apparent that a variety of antigens (eg immunoglobulin, lysozyme, hepatitis B antigen, CEA, and hormones) can be revealed by immunoperoxidase staining of paraffin-embedded routine histological material (for references, see Mason and Taylor (1977)), thus greatly increasing the scope for retrospective immunohistological studies of pathological tissue samples.

A number of techniques have been used for linking peroxidase to specific antibody. The method adopted in the earliest studies was directly to couple the enzyme to antibody via covalent bonds (Avrameas and Uriel, 1966; Nakane and Pierce, 1966). A subsequently developed approach (the 'unlabelled antibody' method) involves the use of an intermediate antibody acting bivalently to link the primary antibody to immune complexes of peroxidase and anti-peroxidase (Mason et al., 1969; Sternberger and Cuculis, 1969). A modification of this technique, the PAP method of

Received for publication 28 November 1977
Sternberger et al. (1970), is probably the mos sensitive immunoperoxidase method currently avail able.

In addition to high sensitivity, unlabelled antibod techniques offer the advantage that no chemica债 modification of either enzyme or antibody is necessary in the preparation of reagents, thus minimising loss of peroxidase or antibody activity

The present paper describes an unlabelleç antibody procedure in which alkaline phosphatase is used to reveal antigens in paraffin sections or blood smears. By combining this procedure with immunoperoxidase staining, two antigens in the same section can be labelled simultaneously in contrasting colours. Since the two antisera 'sandN wiches' are applied at the same time rather thañ sequentially, the only addition to the length of the procedure (compared to the single immunoenzy $w$ matic technique) is the histochemical step for the second enzyme, lasting approximately five minutes.

\section{Material and methods}

BUFFERS

Tris buffered saline $(0.5 \mathrm{M}$ Tris-HC), $\mathrm{pH} 7.6$ diluted 1:10 with $0.15 \mathrm{M}$ saline) was used throughoub as diluent for antisera, enzymes, and peroxidase substrate and for washing slides between incubation 
steps. The alkaline phosphatase substrate was made up in Tris- $\mathrm{HCl}$ buffer (see below).

\section{HISTOCHEMICAL REAGENTS}

Diaminobenzidine, naphthol AS phosphate, and naphthol AS-MX were obtained from Sigma Chemical Co, diazonium salts from Sigma or Raymond Lamb, and horseradish peroxidase (grade 1) from Boehringer.

\section{ALKALINE PHOSPHATASE}

Calf intestinal alkaline phosphatase (Sigma) was obtained as a crude preparation $(1 \cdot 1$ units $/ \mathrm{mg}$ solid, type 1) and as a highly purified grade (1075 units/mg protein, type VII).

\section{ANTISERA}

Antisera were obtained from Dakopatts A/s (rabbit anti-human kappa and lambda light chains, rabbit anti-human lactoferrin, rabbit anti-human lysozyme, swine anti-rabbit IgG) or Miles Laboratories (goat anti-human lysozyme, goat anti-human kappa and lambda light chains, donkey anti-goat IgG, sheep anti-rabbit IgG, goat anti-peroxidase: peroxidase complexes). The specificity of the Dakcpatts antisera has been established during extensive use in this laboratory for immunoperoxidase staining (Taylor and Burns, 1974; Taylor and Mason, 1974; Mason and Taylor, 1975; Mason et al., 1975). The Miles antisera gave staining reactions identical with those of corresponding Dakopatts antisera.

Rabbit anti-alkaline phosphatase antiserum was obtained by immunising a rabbit subcutaneously with four injections of $230 \mu \mathrm{g}$ of alkaline phosphatase (type VII) in Freund's incomplete adjuvant at fortnightly intervals. Serum samples obtained on bleeding six and 14 days after the last injection were pooled. A small amount of enzyme $(2.5 \mathrm{mg})$ was coupled to $0.25 \mathrm{ml}$ of $\mathrm{CNBr}$ activated Sepharose 4B (Pharmacia), and this immunoabsorbent was then used to purify specific anti-alkaline phosphatase antibodies from $0.5 \mathrm{ml}$ aliquots of crude rabbit antiserum. The eluting buffer was $\mathrm{pH} 2.5$ $0 \cdot 1 \mathrm{M}$ glycine $\mathrm{HCl}$, and the total yield (over seven absorption/elution cycles) was $1.3 \mathrm{mg}$ of antibody/ $\mathrm{ml}$ of antiserum. The antibody was concentrated to $6 \mathrm{mg} / \mathrm{ml}$ and stored at $-20^{\circ} \mathrm{C}$.

A similar immunisation schedule was used to raise an anti-horseradish peroxidase antiserum.

TISSUE SAMPLES AND BLOOD SMEARS

Staining reactions were carried out on paraffin sections of aspirated human bone marrow from cases of myeloma and other lymphoproliferative diseases (fixed in half-strength Zenker's solution), on paraffin sections of rectal biopsies and tonsils (fixed in formol saline), and on paraffin sections of a Hodgkin's disease lymph node (fixed in Carnoy's fluid). Normal human blood smears were fixed in buffered formol acetone, as previously described (Mason et al., 1975).

\section{IMMUNOPEROXIDASE STAINING}

Antigens in tissue sections or cell smears were stained as described previously (Mason and Taylor, 1975; Mason et al., 1975) by the peroxidase-antiperoxidase (PAP) technique. In summary, this procedure involves applying to dewaxed paraffin sections or to cell smears the following antiserum sequence: goat anti-human light chains (or goat anti-human lysozyme), donkey anti-goat IgG, and, finally, goat PAP complexes. Each stage lasts 30 minutes and is followed by a wash in buffered saline. Peroxidase activity is revealed using diaminobenzidine and $\mathrm{H}_{2} \mathrm{O}_{2}$ as substrate, and slides are counterstained when necessary with haematoxylin. In control slides, normal rabbit serum was subsituted for the primary antiserum, giving negative cellular staining reactions; see references cited under Antisera for further details of specificity controls. In some experiments tissue sections were pretreated with pepsin $(4 \mathrm{mg} / \mathrm{ml}$ in $0.01 \mathrm{M}$ $\mathrm{HCl}$ at $37^{\circ} \mathrm{C}$ for $15-20$ minutes) before the antisera were applied in order to diminish background staining (Reading, 1977) and to enhance plasma cell reactivity (Huang et al., 1976).

Table 1 Immunoenzymatic technique for labelling cell constituents with alkaline phosphatase

\footnotetext{
1 Rabbit anti-immunoglobulin or lactoferrin

2 Swine or sheep anti-rabbit IgG

3 Rabbit anti-alkaline phosphatase

4 Alkaline phosphatase

5 Fast Blue or Fast Red plus naphthol AS phosphate in pH 9.0 Tris buffer
}

Sections are prepared for application of antisera by dewaxing in xylol and incubation for 10 minutes in normal swine serum (1/5). Blood smears are fixed in formol acetone.

Incubation stages 1-4 each last 30 minutes and are followed by washes in Tris buffered saline pH 7.6. Stage 5 lasts approximately four minutes, and slides are then washed in tap water and mounted in Apathy's mountant.

\section{IMMUNOENZYMATIC LABELLING WITH}

ALKALINE PHOSPHATASE (Table 1)

The first stages of this procedure were, in principle, identical with the immunoperoxidase technique, slides being treated with anti-human light chain antiserum (or rabbit anti-lactoferrin when staining blood smears) followed by swine or sheep antirabbit IgG. Slides were then treated with antialkaline phosphatase antibody (either as whole 
antiserum or as affinity purified specific antibody) followed by alkaline phosphatase. (In some experiments - see results - these two stages were condensed into a single step, ie, anti-alkaline phosphatase and alkaline phosphatase were mixed and applied together to the slides.) As in the immunoperoxidase procedure, all incubation stages lasted 30 minutes and were followed by washing in buffered saline. A substrate solution was prepared by dissolving Fast Blue BBN or Fast Red TR $(0.4-1.0 \mathrm{mg} / \mathrm{ml})$ in Tris $\mathrm{HCl}$ buffer, $0.1 \mathrm{M} \mathrm{pH}$ 9.0 , containing $0.1 \mathrm{mg} / \mathrm{ml}$ naphthol AS phosphate, which was filtered directly onto the slides. In addition to the Fast Blue and Fast Red salts, the following diazonium salts were also tested: Fast Violet B, Fast Blue RR, Fast Black B, and Fast Red Violet LB. In some experiments the substituted naphthol AS-MX (Stage and Avrameas, 1976) was compared to naphthol AS phosphate. After completion of the alkaline phosphatase reaction, slides were washed in tap water, and mounted, with or without prior counterstaining, in Apathy's aqueous mountant.

In some experiments Gomori's technique for revealing alkaline phophatase was assessed as an alternative to the naphthol AS phosphate method (Burstone, 1962). Slides were counterstained with haematoxylin, dehydrated, and mounted in DPX.

\section{DOUBLE IMMUNOENZYMATIC STAINING}

When staining two antigens simultaneously (using both peroxidase and alkaline phosphatase as labels) the two antisera or enzymes for each stage were mixed so as to give the final concentrations found to be appropriate for the individual reagents in preliminary single antigen staining experiments. Slides were then treated with $\mathrm{DAB}$ and $\mathrm{H}_{2} \mathrm{O}_{2}$ to reveal peroxidase labelling, rinsed, and incubated in the alkaline phosphatase substrate. A representative experiment is outlined in Table 2.

\section{Results}

\section{ALKALINE PHOSPHATASE IMMUNOCYTO-} CHEMICAL STAINING

The unlabelled antibody procedure when evaluated on peripheral blood smears (for the detection of polymorph lactoferrin) or on tissue sections (for the detection of plasma cell immunoglobulin or myeloid cell lysozyme) gave clear cytoplasmic staining (Figs 1, 2, 5). This reaction closely resembled in intensity, cellular localisation, and level of background the patterns obtained for these constituents by the PAP immunoperoxidase procedure.
Table 2 Technique for staining two populations of plasma cells in bone marrow sections
Details of a representative experiment:

1 Dewaxed sections incubated in methanol plus $0.3 \% \mathrm{H}_{2} \mathrm{O}_{2}$

2 Normal swine serum $1 / 5$

3 Rabbit anti-lambda light chains $1 / 100$ plus goat anti-kappa light chains $1 / 30$

4 Swine anti-rabbit IgG 1/25 plus donkey anti-goat IgG 1/5

5 Rabbit anti-alkaline phosphatase $1 / 500$ plus alkaline phosphatase $(5.5 \mathrm{U} / \mathrm{ml})$ plus goat PAP $1 / 50$

6 Diaminobenzidine $(0.6 \mathrm{mg} / \mathrm{ml})$ plus $0.01 \% \mathrm{H}_{2} \mathrm{O}_{2}$

7 Naphthol AS phosphate $(0.1 \mathrm{mg} / \mathrm{ml})$ plus Fast Blue BBN $(1.0 \mathrm{mg} / \mathrm{ml})$

Stages $1,3,4$, and 5 last 30 minutes. Stage 2 lasts 15 minutes and $\vec{\omega}$ stages 6 and 7 eight and four minutes respectively. Slides are washedo in buffered saline after stages 1-6.

Results: Lambda plasma cells: Blue Kappa plasma cells: Brown

\section{CHOICE OF SUBSTRATE CONDITIONS}

When using naphthol AS phosphate optimal staining was obtained at $\mathrm{pH} 9.0$ in combination with Fast Blue BBN, Fast Red TR, or Fast RedViolet LB salts at $1.0 \mathrm{mg} / \mathrm{ml}$. Fast Red TR was the $\overrightarrow{0}$ most satisfactory stain for general use since it gaveo an intense red reaction product which contrasted well with haematoxylin (Figs 1 and 5). For doubles immunostaining, however (see below), Fast Blue BBN was preferable because of its clear contras@ with the brown DAB peroxidase reaction producto (Figs 3, 4, 6). The substituted naphthol AS-MX was comparable in staining intensity to naphthol AS phosphate.

Intense staining of alkaline phosphatase labellect cells was also obtained by Gomori's method which yielded a black deposit of cobalt sulphide? However, this reaction, although of similar intensityoto the Fast Blue and Fast Red reactions, did not stain cell cytoplasm as evenly as did the diazoniumo salts (or the immunoperoxidase procedure), although it had the advantages of being compatible withe dehydration and mounting in DPX, and of contrast $\rightarrow$ ing well with haematoxylin counterstaining.

INCUBATION OF SECTIONS WITH ANTIALKALINE PHOSPHATASE AND ALKALINE PHOSPHATASE

The third and fourth stages of the immunoenzymatico sequence (application of anti-enzyme antibodye followed by incubation with enzyme) were initially performed using affinity purified anti-alkaline? phosphatase antibodies (see Methods) and highlyo purified alkaline phosphatase (1075 units/mg). These reagents gave good staining when used ato high dilution (eg, less than $1 \mu \mathrm{g} / \mathrm{ml}$ ). However $\mathbb{\mathbb { D }}$ whole anti-alkaline phosphatase antiserum ino combination with the crude enzyme preparation 


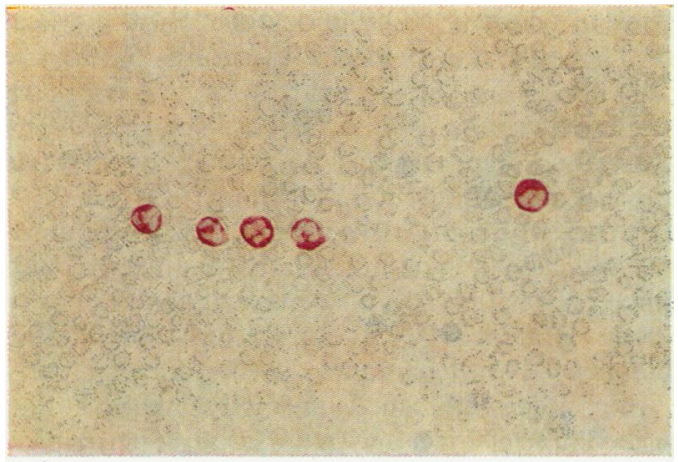

1

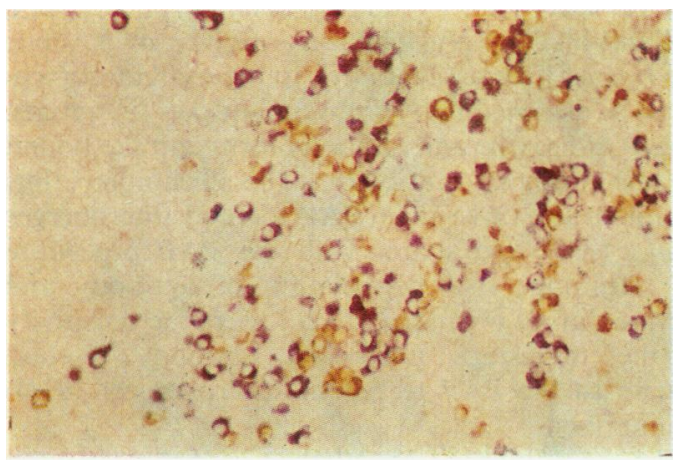

3

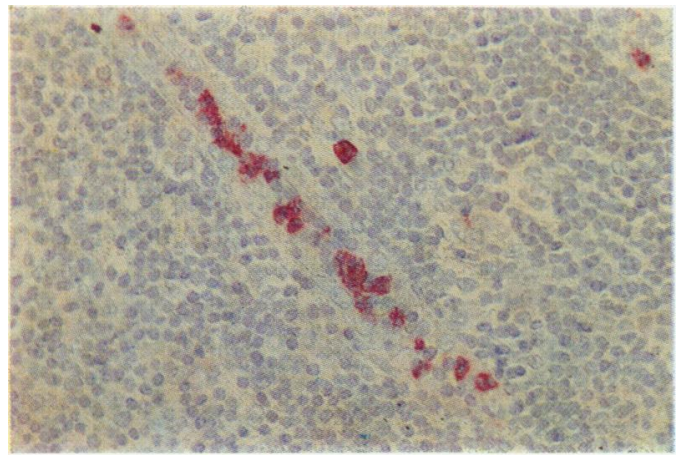

5

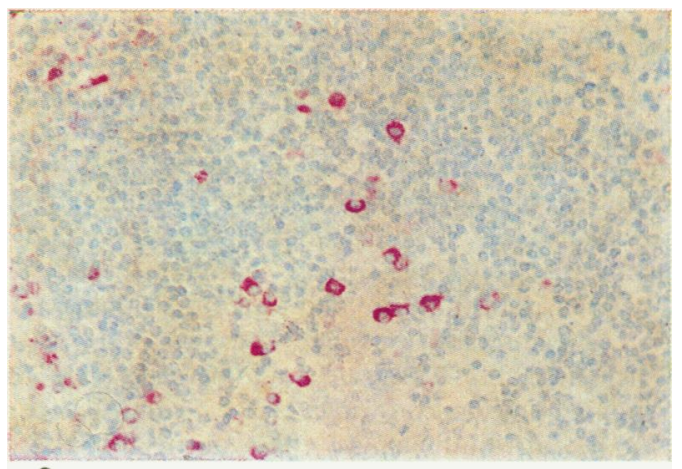

2

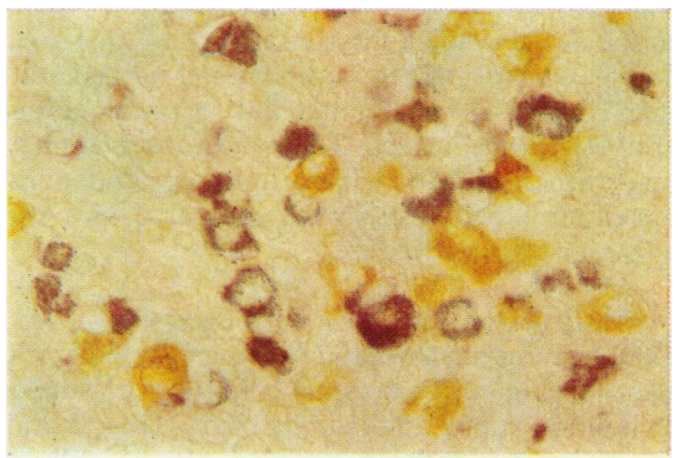

4

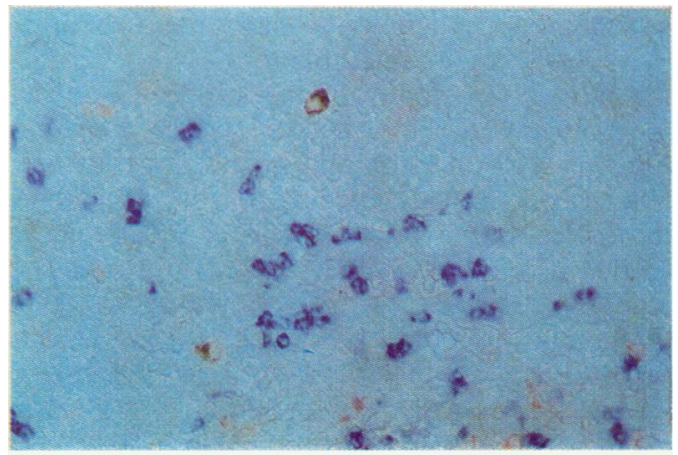

6

Fig. 1 Alkaline phosphatase immunostaining of normal peripheral hlood ne'utrophils for lactoferrin. Note negative lymphocytes. Substrate: Fast Red TR plus naphthol AS-MX, Counterstain: Haematoxylin.

Fig. 2 Alkaline phosphatase immunostaining of plasma cells in human tonsil for kappa light chains. Suhstrate: Fast Red TR plus naphthol AS-MX. Counterstain: Haematoxylin.

Fig. 3 Double immunostaining of same sample of human tonsil for kappa and lambda light chains (blue and hroun respectively). Substrate: Fast Blue $B B N$ plus naphthol $A S-M X$ for alkaline phosphatase, diaminohenzidine $\mathrm{H}_{2} \mathrm{O}_{2}$ for peroxidase. Vo counterstain.

Fig. 4 Higher power view of same section.

Fig. 5 Alkaline phosphatase staining of neutrophil lysozyme in human tonsil. Substrate and counterstain as for Fig. 1.

Fig. 6 Double staining of same sample for neutrophil lysozyme (blue) and plasma cell lamhda light chains (hrown). Suhstrates as for Fig. 3. 
$(1 \cdot 1$ units $/ \mathrm{mg})$ at appropriately higher concentrations gave equally good staining.

After establishing the conditions for staining by the four-stage method, the feasibility of adding the third and fourth stages simultaneously (rather than sequentially) was explored. Staining by this procedure was identical with that observed in the four-stage technique, using either purified antialkaline phosphatase and alkaline phosphatase or crude preparations of antibody and enzyme. When the three- and four-stage methods were compared in combination with a range of dilutions of the primary anti-human light chain antiserum, the two techniques were equally sensitive. However, in contrast to the four-stage procedure, it was necessary in the three-stage technique to use the enzyme solution at a sufficient concentration (relative to the anti-enzyme antiserum) to ensure that soluble complexes (in antigen excess) were formed, rather than insoluble precipitates (at or near antigen: antibody equivalence). The same observation was made when anti-peroxidase antibody and purified horseradish peroxidase were compared in a threeand four-stage procedure.

\section{DOUBLE IMMUNOENZYMATIC STAINING}

Double immunoenzymatic staining (Table 2) yielded clear labelling in contrasting colours of plasma cells containing kappa and lambda chains (Figs 3 and 4) or of immunoglobulin positive plasma cells and lysozyme positive myeloid cells (Fig. 6). The colour of each enzyme reaction product was identical with that obtained in single antigen staining, suggesting that no cross reactions between the two antisera 'sandwiches' were taking place.

Although the ability of this procedure to detect two antigens at the same site (rather than in two different cell populations) was not extensively investigated, it was noted that whereas individual plasma cells in sections (stained for kappa and lambda chains) were either blue or brown, serum in blood vessels and the cytoplasm of atypical Hodgkin's reticulum cells gave an intermediate muddy purple colour reaction, presumably representing polyclonal immunoglobulin. A similar colour was also seen in a proportion of plasma cells when sections were stained simultaneously for IgG and kappa or lambda light chains.

\section{Discussion}

Although the potential value of alkaline phosphatase as an antibody label was established some years ago by Avrameas and his colleagues (Avrameas, 1969; Ternynck and Avrameas, 1976), horseradish peroxidase has found widespread acceptance as the enzyme of choice for immunocytochemical applica- $\stackrel{0}{\overrightarrow{0}}$ tion. The only report in the literature on the use of alkaline phosphatase, apart from the work of $\overrightarrow{\vec{F}}$ Avrameas' group, is the recent description by Druguet and Pepys (1977) on human lymphocyte membrane immunoglobulin labelling.

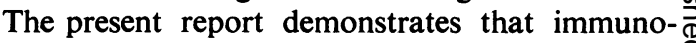
enzymatic labelling of human tissue antigens with $\varrho$ alkaline phophatase is similar in clarity and intensity os to that obtained with horseradish peroxidase $\overrightarrow{0}$ techniques. The techniques used follow closely the four-stage unlabelled antibody method first $\vec{\omega}$ described in 1969 for use with horseradish peroxidase (Mason et al., 1969; Sternberger and Cuculis, 1969). However, it was noted in the present experiments that this procedure can be simplified, without or loss of sensitivity, by adding alkaline phosphatase cि and anti-alkaline phosphatase antibody in a single step (rather than sequentially). In these circumstances $\stackrel{ }{-}$ it can be assumed that soluble complexes (in antigen excess) of enzyme and antibody form and are bound by the bridging antibody. The technique thus resembles the three-stage PAP method (Sternberger et al., 1970) and shares with the PAP procedure the advantage that dissociation of antibody and enzyme during washing (which lowers the sensitivity of the four-stage unlabelled antibody method relative to the PAP technique (Sternberger, 1974)) is minimised.

The combination of alkaline phophatase with $\overrightarrow{\vec{\rho}}$ peroxidase for double immunoenzymatic labelling $\frac{3}{3}$ of two constituents in a single section has not previously been reported. Several groups have reported labelling two cellular constituents by the use of two contrasting substrates for peroxidase? (Nakane, 1968; Vandesande and Dierickx, 1975; Erlandsen et al., 1976; Martin-Comin and Robyn, 1976). However, this approach has the disadvantage that the two immunohistological sandwiches must be applied sequentially so that double labelling by the unlabelled antibody procedure would involve $\frac{7}{2}$ six more incubation steps than are needed for visualisation of a single antigen. Furthermore, this $\mathrm{N}$ procedure entails the possibility of unwanted cross $N$ reactions and antigen denaturation (Campbell and Bhatnagar, 1976).

These considerations led Campbell and Bhatnagar (1976) to develop a double immunoenzymatic $\stackrel{\circ}{\subset}$ staining procedure in which two different enzymes (peroxidase and glucose oxidase) are covalently? coupled to separate antisera. However, this procedure also involved sequential rather than simul- $\frac{0}{\Phi}$ taneous application of antibodies, thus doubling the $\odot$ length of the procedure to a total of 48 hours. $\stackrel{\square}{\square}$ Furthermore, the necessity to prepare antibodies covalently labelled with glucose oxidase, as well as 8 
peroxidase coupled antibody, is an additional technical disadvantage.

The double labelling method described in the present report offers several advantages over previous techniques. The procedure involves only one extra incubation step (lasting less than five minutes) compared to the PAP immunoperoxidase procedure. All reagents, with the exception of rabbit anti-alkaline phosphatase antiserum, are commercially available. This antiserum is readily prepared by a brief immunisation schedule (using a total of less than $1 \mathrm{mg}$ of enzyme) and, although raised against highly purified enzyme, gave identical immunocytochemical staining reactions whether used in combination with purified or with crude enzyme preparations. In the latter instance the anti-alkaline phosphatase antibody presumably specifically selects molecules of pure enzyme and 'ignores' contaminating material which was absent from the preparation used for immunisation.

The existence of a simple and reliable method for the simultaneous immunoenzymatic demonstration of two constituents in paraffin-embedded tissue sections or peripheral blood films suggests a number of applications in a clinicopathological context. Relative ratios of two cell populations and their topographical interrelationships can rapidly and accurately be assessed by this procedure, for example, plasma cells of one immunochemical class versus those of a second type, or lysozyme-positive cells versus immunoglobulin-positive cells (of relevance in cases of leukaemia supervening on myeloma).

In addition to these applications in the context of the identification of different cell populations, it is of interest that the double immunoenzymatic procedure appears to be capable of detecting two antigens within a single cell. This feature is of particular interest in the context of studies of lymphoproliferative disorders such as Hodgkin's disease in which the presence of polyclonal immunoglobulin within proliferating cells has been suspected from staining of adjacent sections (Taylor, 1976) but not directly demonstrated.

Our thanks are due to $\mathbf{M r} \mathbf{J}$. Burns for advice on alkaline phosphate cytochemistry and for providing a number of histochemical reagents; to Dr R. I. Vanhegan for providing tissue samples; to $\mathrm{Dr} T$. Parry for photographic assistance; and to Mrs J. Braidwood for typing the manuscript.

We also gratefully acknowledge the generous contributions of Dakopatts A/s and of the Oxfordshire Area Health Authority (Teaching) Research Fund towards the cost of colour printing.

This work was partly supported by a grant from the Leukaemia Research Fund.

\section{References}

Avrameas, S. (1969). Coupling of enzymes to proteins with glutaraldehyde. Use of the conjugates for the detection of antigens and antibodies. Immunochemistry, 6, 43-52.

Avrameas, S., and Uriel, J. (1966). Méthode de marquage d'antigènes et d'anticorps avec des enzymes et son application en immunodiffusion. Comptes Rendus de l'Académie des Sciences (Paris) (D), 262, 2543-2545. Burstone, M. S. (1962). Enzyme Histochemistry, p. 267. Academic Press, London.

Campbell, G. T., and Bhatnagar, A. S. (1976). Simultaneous visualization by light microscopy of two pituitary hormones in a single tissue section using a combination of indirect immunohistochemical methods. Journal of Histochemistry and Cytochemistry, 24, 448-452.

Druguet, M., and Pepys, M. B. (1977). Enumeration of lymphocyte populations in whole peripheral blood with alkaline phosphatase-labelled reagents. Clinical and Experimental Immunology, 29, 162-167.

Erlandsen, S. L., Hegre, O. D., Parsons, J. A., McEvoy, R. C., and Elde, R. P. (1976). Pancreatic islet cell hormones: distribution of cell types in the islet and evidence for the presence of somatostatin and gastrin within the D cell. Journal of Histochemistry and Cytochemistry, 24, 883-897.

Huang, S. N., Minassian, H., and More, J. D. (1976). Application of immunofluorescent staining on paraffin sections improved by trypsin digestion. Laboratory Investigation, 35, 383-390.

Martin-Comin, J., and Robyn, C. (1976). Comparative immunoenzymatic localization of prolactin and growth hormone in human and rat pituitaries. Journal of Histochemistry and Cytochemistry, 24, 1012-1016.

Mason, D. Y., Farrell, C., and Taylor, C. R. (1975). The detection of intracellular antigens in human leucocytes by immunoperoxidase staining. British Journal of Haematology, 31, 361-370.

Mason, D. Y., and Taylor, C. R. (1975). The distribution of muramidase (lysozyme) in human tissues. Journal of Clinical Pathology, 28, 124-132.

Mason, D. Y., and Taylor, C. R. (1977). Distribution of transferrin, ferritin, and lactoferrin in human tissues. Journal of Clinical Pathology, 31, 316-327.

Mason, T. E., Phifer, R. F., Spicer, S. S., Swallow, R. A., and Dreskin, R. B. (1969). An immunoglobulinenzyme bridge method for localising tissue antigens. Journal of Histochemistry and Cytochemistry, 17, 563-569.

Nakane, P. K. (1968). Simultaneous localization of multiple tissue antigens using the peroxidase-labeled antibody method: a study on pituitary glands of the rat. Journal of Histochemistry and Cytochemistry, 16, 557-560.

Nakane, P. K., and Pierce, G. B., Jr (1966). Enzyme labeled antibodies: preparation and application for the localization of antigens. Journal of Histochemistry and Cytochemistry, 14, 929-931.

Reading, M. (1977). A digestion technique for the reduction of background staining in the immunoperoxidase 
method. Journal of Clinical Pathology, 30, 88-90.

Stage, D. E., and Avrameas, S. (1976). Detection of Anti-TNP antibody forming cells (AFC) with TNPenzyme and TNP-Fab anti-enzyme conjugates. Journal of Immunological Methods, 10, 105-118.

Sternberger, L. A. (1974). Immunochemistry, p. 182. Prentice Hall, New Jersey.

Sternberger, L. A., and Cuculis, J. J. (1969). Method for enzymatic intensification of the immunocytochemical reaction without use of labeled antibodies (Abstract). Journal of Histochemistry and Cytochemistry, 17, 190. Sternberger, L. A., Hardy, P. H. Jr., Cuculis, J. J., and Meyer, H. G. (1970). The unlabeled antibody method of immunohistochemistry. Journal of Histochemistry and Cytochemistry, 18, 315-333.

Taylor, C. R. (1976). An immunohistological study of follicular lymphoma, reticulum cell sarcoma and Hodgkin's disease. European Journal of Cancer, 12, 61-75.

Taylor, C. R., and Burns, J. (1974). The demonstration of plasma cells and other immunoglobulin-containing cells in formalin-fixed, paraffin-embedded tissues

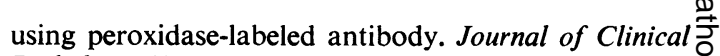
Pathology, 27, 14-20.

Taylor, C. R., and Mason, D. Y. (1974). The immuno- $\overrightarrow{\vec{F}}$ histological detection of intracellular immunoglobulin in formalin-paraffin sections from multiple myeloma and related conditions using the immunoperoxidase technique. Clinical and Experimental Immunology, 18, 417-429.

Ternynck, T., and Avrameas, S. (1976). A new method using P-benzoquinone for coupling antigens and antibodies to marker substances. Annales d'Im-, munologie, 127c, 197-208.

Vandesande, F., and Dierickx, K. (1975). Identification $\vec{\omega}$ of the vasopressin producing and of the oxytocin producing neurones in the hypothalamic magnocellular? neurosecretory system of the rat. Cell and Tissue Research, 164, 153-162.

Requests for reprints to: Dr D. Y. Mason, Harkness Laboratory, The Radcliffe Infirmary, Oxford, OX2 6HE. 